quent dipping of the hands into solutions of formalin. None have suffered locally. One, however, used to say that he frequently noticed a red itching rash over his chest after contact with formalin. The rash used to pass off in a few hours. Besides the student mentioned, five or six others worked for several weeks at mounting specimens, but none complained of being troubled in any way by the use of formalin.

\title{
Herpes Gestationis.
}

BY BENJAMIN JONES, L.R.C.P.

As Herpes gestationis is a somewhat rare complication of pregnancy, I considered that the following case might be of sufficient interest to be worth recording:-

Mrs. S., aged 29, was confined of her first child on June 19th. Her previous health had been excellent, and she had never suffered from any form of skin eruption till a week before her confinement. Her mother had a healthy skin, but her father was subject to eczema. Her grandmother in each of five pregnancies had suffered from a rash similar in appearance to that of the patient. In this case the dermatitis was ushered in by troublesome itching and burning sensations about the umbilicus, which developed two days later about the toes.

On June 20th, the day after delivery, she complained of it to me, and on examination I found a multiform rash, consisting of papules, urticarial lesions and vesicles around the umbilicus, extending into the groins, and on the feet. In the latter situations the lesions were mostly vesicular. No pustules were present. The next day the eruption had extended over the arms and legs, on both their extensor and flexor aspects, and over the body generally. On the face only a few urticarial spots were noted. The lesions showed a definite grouping on the legs and arms.

On June 23rd large bullæ appeared on both the big toes, and a few smaller ones on the soles and sides of the feet. There were no bullæ on other parts of the body. She complained of itching, burning, and even pain in the big toes. The itching, she said, was much worse at night. I called in Dr. MacLeod in consultation, and he agreed with my diagnosis. 
The puerperium was not in the least interfered with, and on June 30th the rash had almost entirely disappeared.

\section{A Case of Wandering Foma.}

BY BERNHARD SMITH,

Surgeon P. and O. Steam Navigation Company.

THe following case is worthy of note on account of its characteristic symptoms. H. B., aged 28 , has been married for two years. He was formerly a sailor, and states that when in the tropics he was never affected by "prickly heat" nor by the bites of mosquitoes. He has been under treatment for the present condition since July, 1899. He then first noticed a swelling of the eyelid, which occurred when he was on a cycling tour. Since that time he has had attacks occurring very irregularly, usually two in a week, and then perhaps he may have a month's relief. Translucent painless swellings appear chiefly on the face, but they have occurred on all parts of his body. They commence during sleep, and usually fade completely about 3 o'clock P.M. The attack depicted in the accompanying photograph lasted for forty-eight hours.

$\mathrm{He}$ is of sedentary habits, complains sometimes of dyspepsia, but is regular in his mode of life and enjoys good health. $\mathrm{He}$ has had one attack of Herpes zoster, and one sister is subject to Urticaria. The family history gives evidence of a tendency to nervous diseases.

Treatment by means of purgatives, change of occupation, regulation of diet, have all been tried withont producing the slightest result, so far as the attacks of cedema are concerned; the drugs which have been used-arsenic, iodide of potash and strychninehave also failed in producing any beneficial result.

\section{Mycosis Fungoides. \\ BY LAURENCE POTTS, M.R.C.S.}

THe following supplementary note on Mrs. G., the first of the three cases of Mycosis fungoides published in this Journal in the May and June numbers of last year by Drs. Galloway and MacLeod, is of special interest. This patient, while under treatment in Charing 